Article

\title{
Drone-Based High-Resolution Tracking of Aquatic Vertebrates
}

\author{
Vincent Raoult 1,2,*iD, Louise Tosetto ${ }^{2,3}$ and Jane E. Williamson 2,3,4 \\ 1 School of Environmental and Life Sciences, University of Newcastle, 11 Chittaway rd., \\ Ourimbah, NSW 2258, Australia \\ 2 Department of Biological Sciences, Macquarie University, Macquarie Park, NSW 2109, Australia; \\ louise.tosetto@hdr.mq.edu.au \\ 3 MQMarine, Macquarie University, Sydney, NSW 2109, Australia; jane.williamson@mq.edu.au \\ 4 Sydney Institute of Marine Science, Mosman, NSW 2088, Australia \\ * Correspondence: Vincent.raoult@newcastle.edu.au
}

Received: 9 October 2018; Accepted: 7 November 2018; Published: 8 November 2018

\begin{abstract}
Determining the small-scale movement patterns of marine vertebrates usually requires invasive active acoustic tagging or in-water monitoring, with the inherent behavioural impacts of those techniques. In addition, these techniques rarely allow direct continuous behavioural assessments or the recording of environmental interactions, especially for highly mobile species. Here, we trial a novel method of assessing small-scale movement patterns of marine vertebrates using an unmanned aerial vehicle that could complement longer-term tracking approaches. This approach is unlikely to have behavioural impacts and provides high accuracy and high frequency location data $(10 \mathrm{~Hz})$, while subsequently allowing quantitative trajectory analysis. Unmanned aerial vehicle tracking is also relatively low cost compared to single-use acoustic and GPS tags. We tracked 14 sharks for up to $10 \mathrm{~min}$ in a shallow lagoon of Heron Island, Australia. Trajectory analysis revealed that Epaulette sharks (Hemiscyllium ocellatum) displayed sinusoidal movement patterns, while Blacktip Reef Sharks (Carcharhinus melanopterus) had more linear trajectories that were similar to those of a Lemon shark (Negaprion acutidens). Individual shark trajectory patterns and movement speeds were highly variable. Results indicate that Epaulette sharks may be more mobile during diurnal low tides than previously thought. The approach presented here allows the movements and behaviours of marine vertebrates to be analysed at resolutions not previously possible without complex and expensive acoustic arrays. This method would be useful to assess the habitat use and behaviours of sharks and rays in shallow water environments, where they are most likely to interact with humans.
\end{abstract}

Keywords: UAV; coral reef; behaviour; sharks; acoustics; GPS; spatial dynamics; Epaulette; Carcharhinid; whales

\section{Introduction}

Understanding animal movement requires information on foraging decisions, spatial use, and the distributions of populations [1]. While large-scale movements may be influenced by reproductive requirements or temperature [2], smaller-scale movement patterns of animals may be driven by food patches, habitat, or inter and intraspecific interactions between predator and prey, or commensal relationships [3,4]. Insight into how and why animals move within and across environments can be obtained by understanding the relationship between the environment and movement trajectories $[5,6]$. However, inshore aquatic areas, where the majority of marine vertebrates occur, are inherently difficult to sample and are the areas most threatened by human activities [7]. Gaining an understanding of the spatial dynamics of larger vertebrates in these coastal zones will facilitate better management of common anthropogenic threats and abatements. 
Determining the small- and large-scale movement patterns of large marine vertebrates, such as elasmobranchs, cetaceans, pinnipeds, and reptiles, forms an integral part of the conservation and management of these species [8-12]. Many studies in movement ecology focus on establishing the scale or existence of migratory patterns [13-15] and ecologically significant areas, where marine vertebrates may congregate [16-18]. While such information is useful for management purposes, understanding individual movement patterns on small scales may allow more accurate predictions of large-scale behaviours and a greater understanding of the ecological roles of these animals within marine ecosystems [19-21]. For example, a slow rise in the number of global shark-human interactions has also led to calls for a greater understanding of shark behaviour at fine scales in shallow coastal areas, where sharks may interact with humans $[22,23]$. The primary approach to date in obtaining such movement data on individual marine vertebrates relies on the use of intermittent data via acoustic or satellite tags.

In addition to movement patterns, tagging technology now has the ability to incorporate abiotic information and activity data from accelerometers that can be used to infer behavioural responses [24,25] and social interactions [26,27] of marine vertebrates within their environment. However, tag data alone are unable to provide a complete understanding of marine vertebrate movement and behaviour because the behaviours that may occur can only be surmised from the data, often with the increasing drift of dead reckoning data [28,29]. Furthermore, acoustic tags (often single-use) and receiver arrays are prohibitively expensive, especially in remote or shallow environments, such as inshore reefs, where lower detection probabilities require higher receiver densities [30], or if more complex accelerometer or pop-up satellite tags are used. Active boat-based acoustic tracking mitigates some of these issues, but these tracks are shorter than using receivers and still do not directly observe behaviours [31-33]. Transmitter tags communicate intermittently, with intervals ranging from seconds to hours, meaning current tracking methods are generally not continuous. Tagging approaches also require capture and tag attachment, which have welfare implications and may impact the behaviour of animals for substantial periods post-tagging, especially for smaller species or juveniles [34-37]. Efforts have been made to reduce tagging stress and complexity [38,39], but the development of tracking methods that require no direct interaction with the tracked animals is preferable, and could also be used to complement tracking data in shallow environments, such as mangroves or sand flats, where other methods are less effective or practical.

Unmanned aerial vehicles (UAVs), also known as drones, provide an approach that allows small-scale, high-accuracy tracking of movement patterns over short time scales. The recent use of UAVs in marine behavioural studies has been relatively well received due to their relatively low cost, ease of use, and the new perspectives and approaches they can provide [4,40-43]. UAVs can rapidly collect large amounts of continuous data, and researchers are only beginning to develop new uses for this technology. For example, UAVs have been used to assess the social interactions and local densities of sharks [44-46], the use of cleaning stations by marine turtles [4], and the body condition of whales [43]. Since UAVs are relatively recent, novel applications of drone technology for ecological applications are likely to continue to be developed in the coming years [47].

Studies that use UAVs rely primarily on visual data provided by the machine; however, one data stream that has largely been unused is that provided by the inertial management unit (IMU). To facilitate the piloting of these machines by automatically stabilising the aircraft, commercial and recreational UAVs collect dozens of environmental parameters, such as altitude, specific force, angular acceleration, and GPS coordinates, multiple times per second at levels of accuracy significantly greater than those gathered by acoustic tracking. By manually flying a UAV directly above a shark of interest, it should be possible to 'track' the movement of sharks with a high degree of accuracy, to perform trajectory analyses to highlight individual movement behaviours, and to combine those data with visual records of behaviours. The added benefit of such an approach is that no direct interaction with the shark occurs, meaning that observed behaviours and movements would not be affected by human 
interactions. In addition, the use of UAVs for tracking could allow supplemental small-scale tracking at much lower cost than other approaches, since the only cost is the initial purchase of the UAV.

This study trialled the use of UAVs in short-term tracking of marine vertebrates by tracking different species of sharks in a shallow reef lagoon environment. Each species has varied habitat use, perceived ability to move, and ecological requirements. Epaulette sharks (Hemiscyllium spp.) are small $(<107 \mathrm{~cm} \mathrm{TL})$ tropical benthic cat sharks [48] that are primarily known for their extreme tolerance of hypoxic conditions [49-51]. While some studies suggest these sharks move very little during low tides, their movement and behaviour in reef lagoons are still poorly understood [52,53]. By contrast, Reef sharks (Carcharhinid spp.) are much larger $(>1.5 \mathrm{~m})$ and some of the most widely studied species of sharks [54-56], yet their habitat use in shallow lagoon environments is poorly understood due to the difficulties in accessing these environments. In addition, one Lemon shark was also tracked; a species that has been extensively studied in shallow environments [35,57]. We assessed whether trajectory analyses could be performed on these data, and whether patterns in trajectories could be detected within and between species of shark. These results assess the feasibility of this approach to tracking small-scale, high-accuracy movement and behaviour of marine vertebrates in shallow environments.

\section{Materials and Methods}

\subsection{Drone Piloting and Tracking}

Monitoring the movement patterns of sharks was conducted in April 2017 and 2018 at mid to low tides in a shallow reef habitat at Heron Island, Great Barrier Reef, Australia (23.4423 $\left.{ }^{\circ} \mathrm{S}, 151.9148^{\circ} \mathrm{E}\right)$. These shallow reefs are dominated by sand separated by patch reef, and are isolated from the ocean during low tides [58]. Lower tides were monitored in this study to allow easier visibility through wave breaks. Wind patterns on the tracking days ranged from 5 to 17 knots. The drone used in this study was an off-the-shelf DJI Phantom 3 Professional ${ }^{\circledR}$, flown in GPS mode with the DJI GO app on an iPad Mini. The stock camera carried by this drone has an $\mathrm{f} / 2.8$ lens with a $94^{\circ}$ field of view which is capable of recording 1080p footage at over 30 frames per second and to which we fitted a polarised lens to reduce reflections on the surface of the water. Flight caching (which records over 50 flight parameters, including altitude, horizontal and vertical speeds, and GPS coordinates in real time) was enabled, and the drone was manually piloted over the scientific research zone at an altitude of $15 \mathrm{~m}$ when searching for Epaulette sharks, and $40 \mathrm{~m}$ when searching for larger sharks. The UAV was flown in a "S" search pattern until a shark was spotted, then the drone was immediately lowered from 15 to 2-3 m altitude and manually hovered directly above the shark. Flown in this fashion, the GPS location of the drone was directly above the shark, allowing the recorded flight path of the drone to act as a reliable proxy for the position of the shark. A high-resolution 1080p video at $30 \mathrm{fps}$ was recorded of the entire 'track' session of each shark (Figure 1), which also allowed us to determine when a track was started during analyses (record on and off are parameters stored by the UAV) and record behaviours of interest. Once a shark was spotted, the UAV was used to track it until the shark was lost (e.g., due to surface glint or uncertainty that it was hiding in a coral patch) or until the battery of the drone was at $30 \%$ (after which long-term battery life can be affected). See Table 1 for a summary of this approach. Only one shark was tracked at a time. This research was conducted under Macquarie University's animal ethics research permit ARA 2016/019. 
Table 1. Methodological process for drone-based animal tracking flights.

\begin{tabular}{cl}
\hline Step & \multicolumn{1}{c}{ Process } \\
\hline 1 & Check for appropriate weather conditions (low wind <10 kph = optimal, maximum of $30 \mathrm{kph})$. \\
\hline 2 & Take off with drone and fully-charged battery, fly with camera pointed directly down. \\
\hline 3 & $\begin{array}{l}\text { Fly S-shaped search pattern above area of interest at 15-50 m altitude, depending on size of target } \\
\text { species. Adjust height accordingly. }\end{array}$ \\
\hline 4 & $\begin{array}{l}\text { Once target species is spotted, immediately centre animal in the dead centre of viewing screen and } \\
\text { descend to 2-5 m altitude. }\end{array}$ \\
\hline 6 & $\begin{array}{l}\text { Start recording video to record behaviours and aid in data processing, } \\
\text { jagged and large inputs (this is true of any remote piloting, but especially in this case). }\end{array}$ \\
\hline 7 & $\begin{array}{l}\text { Continue tracking until animal is lost or battery gets to the 30\% mark (this will prevent long-term } \\
\text { battery degradation). }\end{array}$ \\
\hline
\end{tabular}

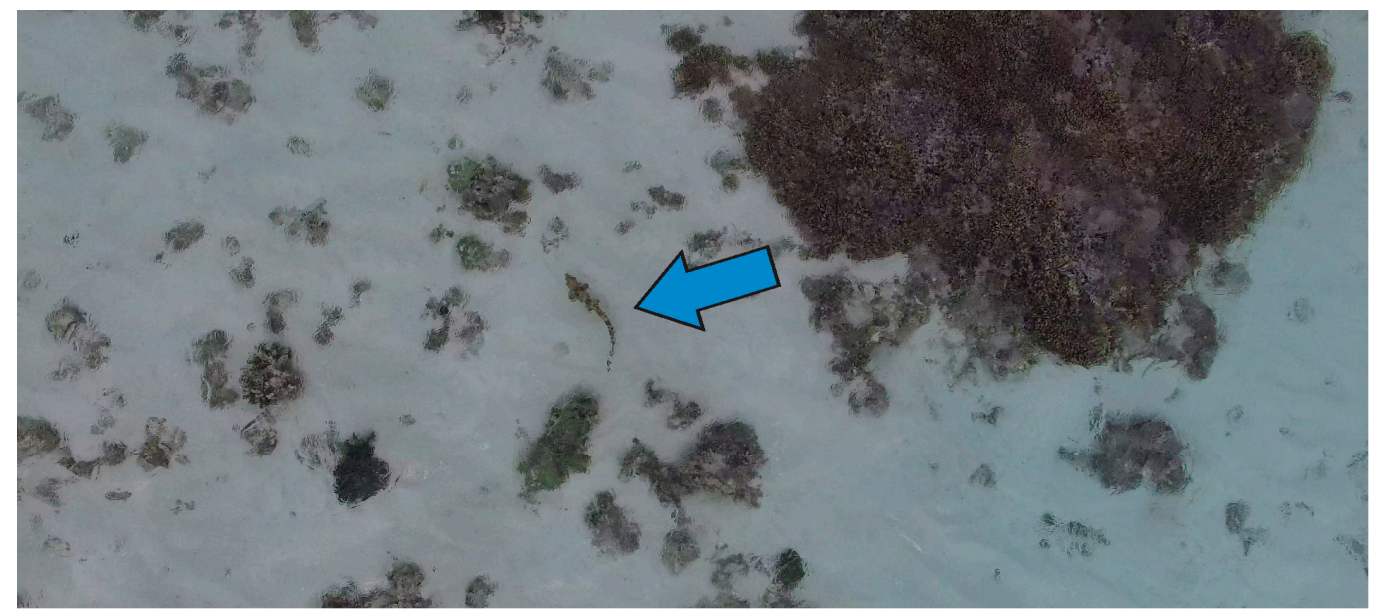

Figure 1. Aerial view from the unmanned aerial vehicle (UAV) while tracking movement and behaviour of an Epaulette shark at an altitude of $\sim 2 \mathrm{~m}$; a shark with an approximate length of $50 \mathrm{~cm}$ is indicated by the blue arrow.

\subsection{Measurement Accuracy}

Measurement accuracy, in this case the measured coordinate error relative to the true position of the animal, should be measured when testing tracking solutions, as it can affect how results are interpreted [59]. Previous studies have found that when topographical data are not of interest (as is the case here), the horizontal accuracy of UAV inbuilt GPS data can be in the sub- $10 \mathrm{~cm}$ range without requiring ground control points (GCPs) [60], and thus we estimated that the measurement accuracy from our UAV is in a similar range. In environments with more than 15 GPS satellites in range, this accuracy is likely to be greater still, and conversely accuracy would be lower in environments with fewer than 10 satellites in range.

While we did not quantify measurement accuracy during this study, the greatest source of measurement error associated with this method is likely to be pilot error. This would cause the UAV to deviate from its position above the tracked animal. In windy conditions, piloting skill becomes more important to produce accurate measurements. Wind-induced error could be corrected by attempting to fly over a stationary point for $30 \mathrm{~s}$ before a track was commenced. The movement over this time could then be used to correct movement rates for any subsequent tracking data. Quantifying manual flight accuracy is more difficult, but pilots could undergo a standardised flight path (or 'track') and 
use error against the true path to correct for errors during subsequent flights. We would expect that measurement error would decrease over time as pilots develop their skills with this approach.

\subsection{Data Preparation}

Logged flight data were downloaded from the UAV using iTunes, and a csv file for each flight log was extracted using the TXTlogtoCSVtool [61], though many other freely available online tools exist that allow similar data to be extracted from the flight logs. The DJI series of UAVs record flight logs at a frequency of $10 \mathrm{~Hz}$, but only GPS coordinates, altitude, time, and the status of video recording were used in this study. The 'recording on' readings in the flight logs, which indicate that video was being recorded, were used to identify tracks of interest within the flight logs, which included data from the moment the UAV was switched on. Flight altitude was then used to assess when the 'track' commenced, designated as when the UAV lowered itself to recording height (2-3 m altitude). The primary variables of interest for this research were GPS coordinates and time of data point, since those allow the extrapolation of other variables of interest. Data for all flight logs were then collated before being loaded into R software V 3.4.4 through RStudio [62].

For a detailed procedure for data processing, we have included an attachment with the R script produced by this study (Supplementary Information). On some days, flight conditions were near the upper limits of the capabilities of the DJI Phantom 3 in GPS mode $(\sim 30 \mathrm{~km} / \mathrm{h})$ : This made many corrections necessary to compensate for gusts of wind, and it was difficult to maintain the drone directly above the shark. This could result in a total track distance that was greater than that of the shark or inaccuracies in the recorded track. To reduce these effects and produce a more homogenous track, 5-s localised smoothing was used on the GPS tracks. Since the DJI Phantom records data at $10 \mathrm{~Hz}$, this meant tracks were smoothed over 50 data points. Smoothed tracks were calculated using the 'ave' function for creating figures of tracks with the ggmap package [63] using satellite imagery provided by Google. For trajectory analysis, GPS coordinates were transformed into metric $X$ and $\mathrm{Y}$ coordinates using the 'rgdal' package and transformed into individual tracks using a processing function (Supplemental Data).

\subsection{Data Analysis}

The aim of these analyses was to extract quantitative trajectory metrics that could be used to characterise individual and species-specific movement patterns on small scales. The method and variables extracted here from the data are just some possibilities, and other approaches, such as state-space models or hidden Markov models could be applied here, depending on the desired metrics $[64,65]$. The trajr package [66] was used throughout the data analyses. Trajr provides a toolkit for trajectory analysis by including numerous metrics to quantitively describe the movement behaviour of animals. All tracks were initially smoothed using the TrajsmoothSG function to correct for inaccuracies in flight tracks. Variables available from this package extracted from each track were: Mean speed, the standard deviation of the speed, total track distance, total track duration, sinuosity, Emax (a measure of straightness), and 'pause interval'. The 'pause interval' was used to estimate the frequency per minute of pauses in movement where speed was below $0.2 \mathrm{~m} \cdot \mathrm{s}^{-1}$ for at least $5 \mathrm{~s}$. This was used as a way of assessing rest or foraging events when the sharks were relatively immobile. The $0.2 \mathrm{~m} \cdot \mathrm{s}^{-1}$ cut-off was chosen as roughly a quarter of the mean movement speed for the species. Trajr can calculate the periodicity of movement patterns; however, the number of data points in the tracks presented here $(>4000)$ caused processing bottlenecks that resulted in calculation errors of unknown magnitude, so this measure was not included. The relationships between species of shark and the variables listed above were then examined visually using a Principle Correspondence Analysis.

\section{Results}

In total, twenty-six 15- to 20-min flights were conducted searching for and tracking sharks. Fourteen sharks were successfully tracked for three to eleven minutes, including nine Epaulette sharks 
(Hemiscyllium ocellatum; Figure 2), four Blacktip Reef sharks (Carcharhinus melanopterus; Figure 3), and one Lemon shark (Negaprion acutidens). Animations of these tracks can be accessed in the Supplemental Information. Trajectory data were successfully extracted from all tracks (Table 2). The trajectories of individual sharks were highly variable, both within and between species, with some sharks having large numbers of pauses, and others swimming continuously during the tracks (Figure 4). Principle Correspondence Analysis suggested that sinuosity, interval numbers, and Emax (straightness) were species-specific characteristics, while the standard deviation of movement speed was independent of species (Figure 5). Three natural feeding or attempted feeding events were recorded: Two for Blacktip Reef sharks and one for Epaulette sharks. In Blacktip Reef sharks, these feeding events were associated with more sinuous and less straight trajectories (sharks 12 and 13, Table 2).

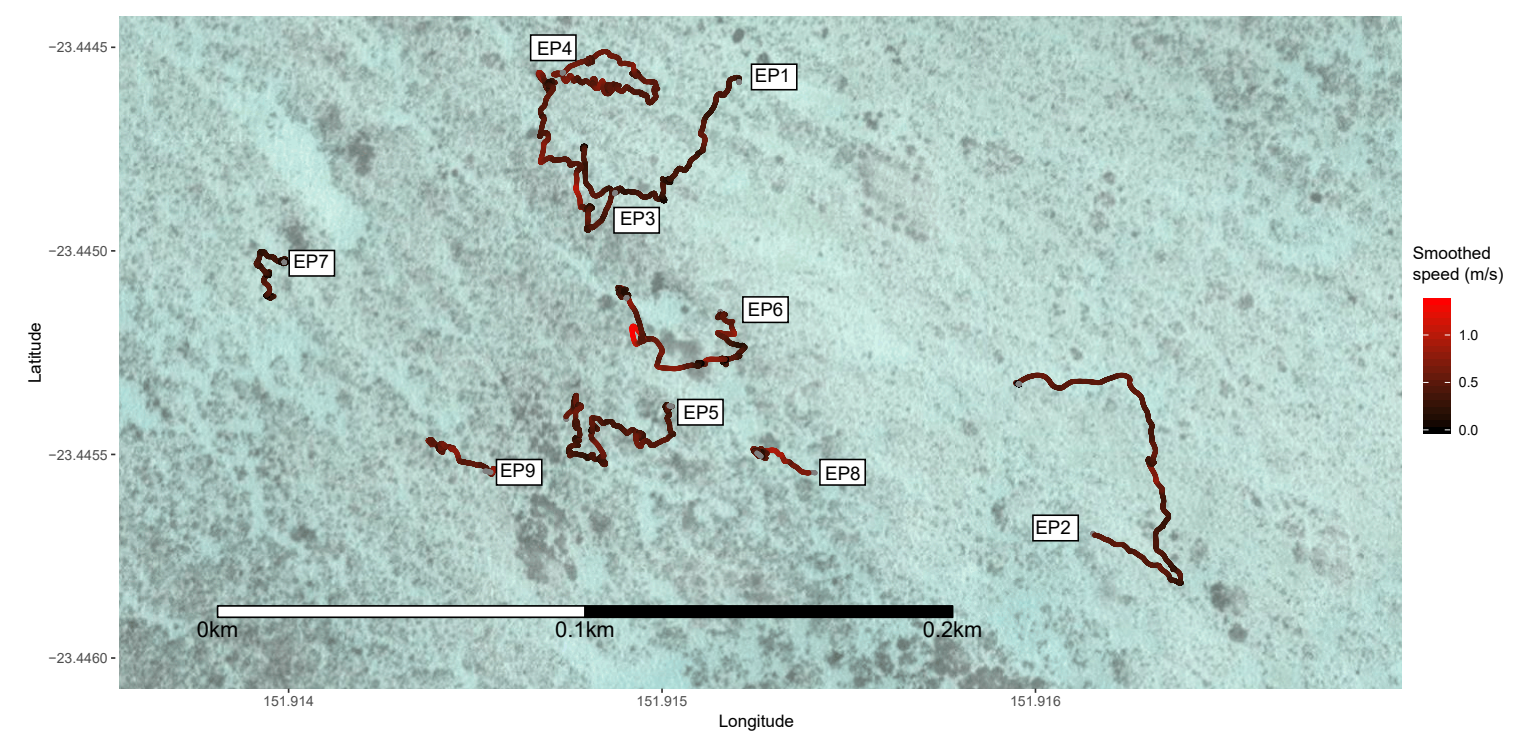

Figure 2. Locally-smoothed Epaulette shark (Hemiscyllium ocellatum) tracks and movement speed recorded at Heron Island reef crest using a UAV. Satellite imagery courtesy of Google.

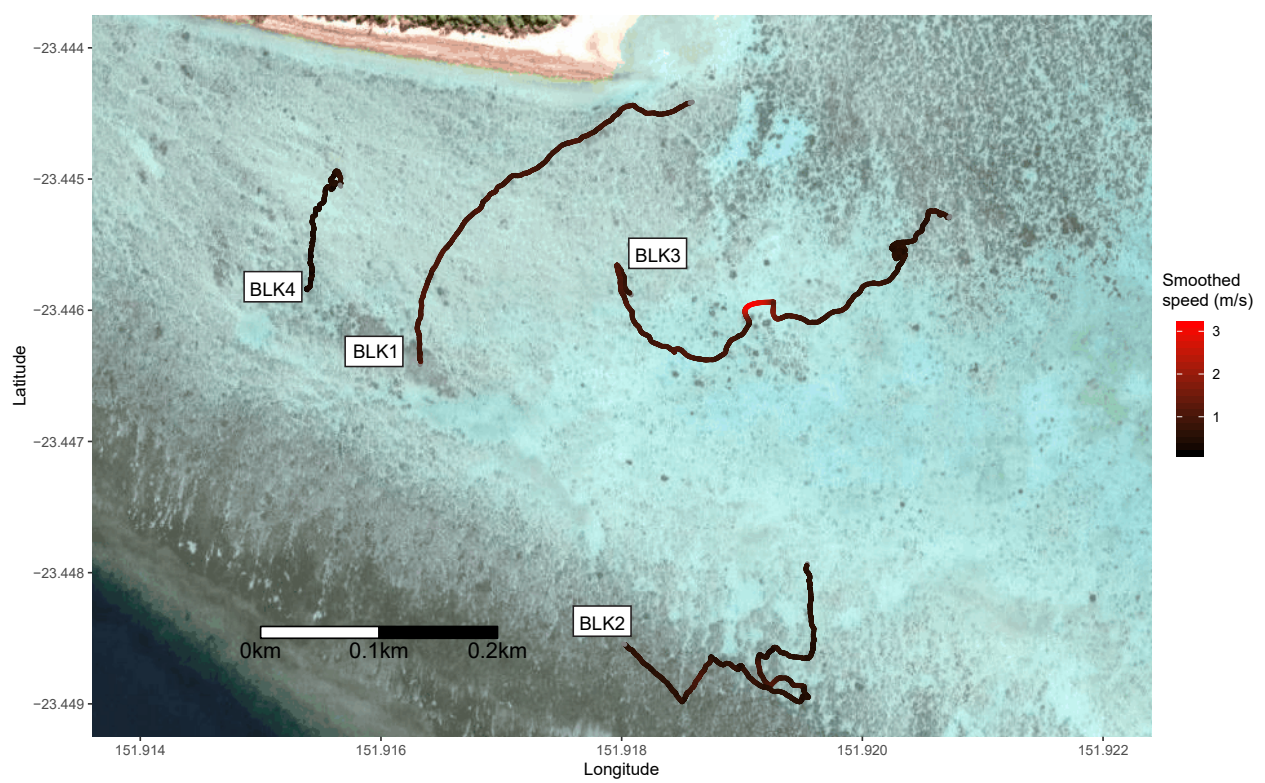

Figure 3. Locally-smoothed Blacktip Reef Shark (Carcharhinus melanopterus) tracks and movement speed recorded at Heron Island reef crest using a UAV. Satellite imagery courtesy of Google. 
Table 2. Results of trajectory analyses from smoothed GPS tracks of sharks observed in Heron Island lagoon.

\begin{tabular}{|c|c|c|c|c|c|c|c|c|c|c|}
\hline $\begin{array}{c}\text { Track } \\
\text { Number }\end{array}$ & Species & $\begin{array}{l}\text { Estimated } \\
\text { Length }(\mathrm{m})\end{array}$ & $\begin{array}{l}\text { Duration of } \\
\text { Track (s) }\end{array}$ & $\begin{array}{c}\text { Distance } \\
\text { Travelled (m) }\end{array}$ & $\begin{array}{c}\text { Mean } \\
\text { Speed }(\mathrm{m} / \mathrm{s})\end{array}$ & $\begin{array}{c}\text { SD of } \\
\text { Speed }(\mathrm{m} / \mathrm{s})\end{array}$ & Sinuosity & $\operatorname{Emax}\left(10^{3}\right)$ & $\begin{array}{l}\text { Pauses Greater } \\
\text { than } 5 \mathrm{~s}(/ \mathrm{min})\end{array}$ & $\begin{array}{c}\text { Observed } \\
\text { Foraging }\end{array}$ \\
\hline EP1 & Epaulette & $<0.7$ & 406.3 & 116 & 0.29 & 0.21 & 0.92 & 4.36 & 1.03 & Yes \\
\hline EP2 & Epaulette & $<0.7$ & 377.7 & 160 & 0.42 & 0.25 & 0.81 & 6.34 & 0.48 & No \\
\hline EP3 & Epaulette & $<0.7$ & 429.5 & 172 & 0.40 & 0.26 & 0.87 & 5.99 & 0.56 & No \\
\hline EP4 & Epaulette & $<0.7$ & 350.6 & 169 & 0.48 & 0.23 & 0.80 & 7.56 & 0 & No \\
\hline EP5 & Epaulette & $<0.7$ & 602.8 & 222 & 0.37 & 0.23 & 0.95 & 4.85 & 0.40 & No \\
\hline EP6 & Epaulette & $<0.7$ & 468.9 & 179 & 0.38 & 0.36 & 0.97 & 4.50 & 0.90 & No \\
\hline EP7 & Epaulette & $<0.7$ & 316.6 & 69 & 0.22 & 0.19 & 1.46 & 2.12 & 2.08 & No \\
\hline EP8 & Epaulette & $<0.7$ & 301.8 & 117 & 0.39 & 0.28 & 1.04 & 4.29 & 0.40 & No \\
\hline EP9 & Epaulette & $<0.7$ & 185.7 & 89 & 0.48 & 0.27 & 0.86 & 5.99 & 0 & No \\
\hline BLK1 & Blacktip & $>1.25$ & 378.7 & 386 & 1.02 & 0.31 & 0.14 & 226.91 & 0 & No \\
\hline BLK2 & Blacktip & $>1.25$ & 680.6 & 454 & 0.67 & 0.26 & 0.19 & 116.03 & 0 & No \\
\hline BLK3 & Blacktip & $>1.25$ & 645.5 & 562 & 0.87 & 0.45 & 0.26 & 69.24 & 0 & Yes \\
\hline BLK4 & Blacktip & $>1.25$ & 300.2 & 161 & 0.54 & 0.17 & 0.40 & 29.13 & 0 & Yes \\
\hline LEM1 & Lemon & $>1.25$ & 357.4 & 286 & 0.80 & 0.23 & 0.20 & 107.39 & 0 & No \\
\hline
\end{tabular}



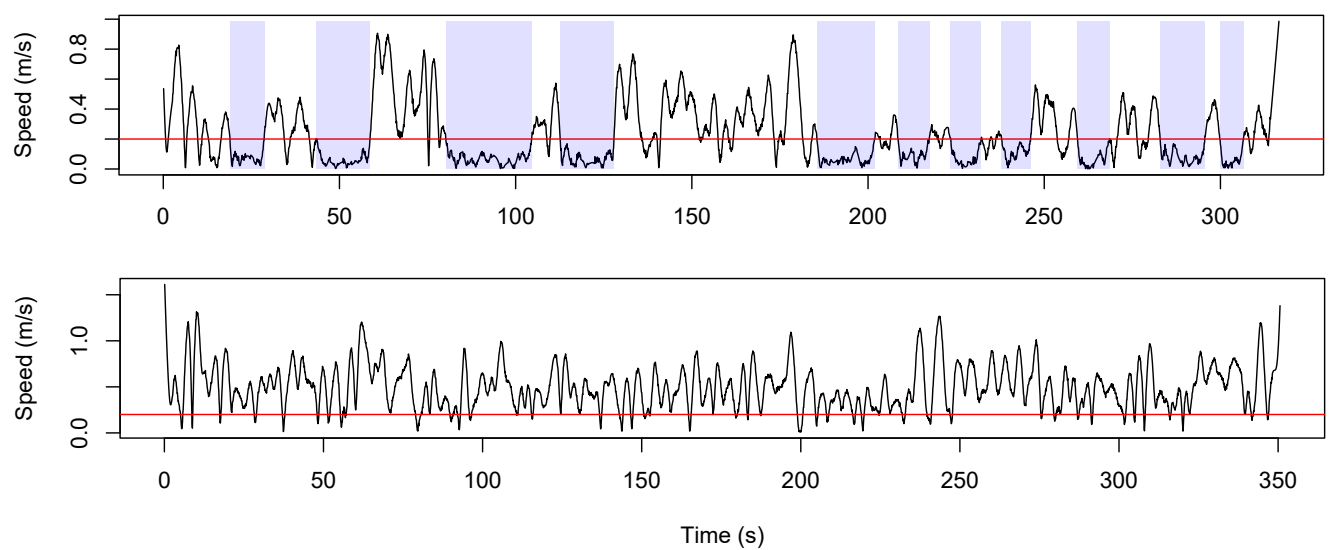

Figure 4. Divergent swim modes of two Epaulette sharks (Hemiscyllium ocellatum) extracted from trajectory data. Notice the large number of 'pauses' in swimming greater than $5 \mathrm{~s}$ in length (in blue) in the top track, compared to no pauses in a track of similar length. The red line represents a slow or stopped movement speed threshold roughly a quarter of peak swim speeds.

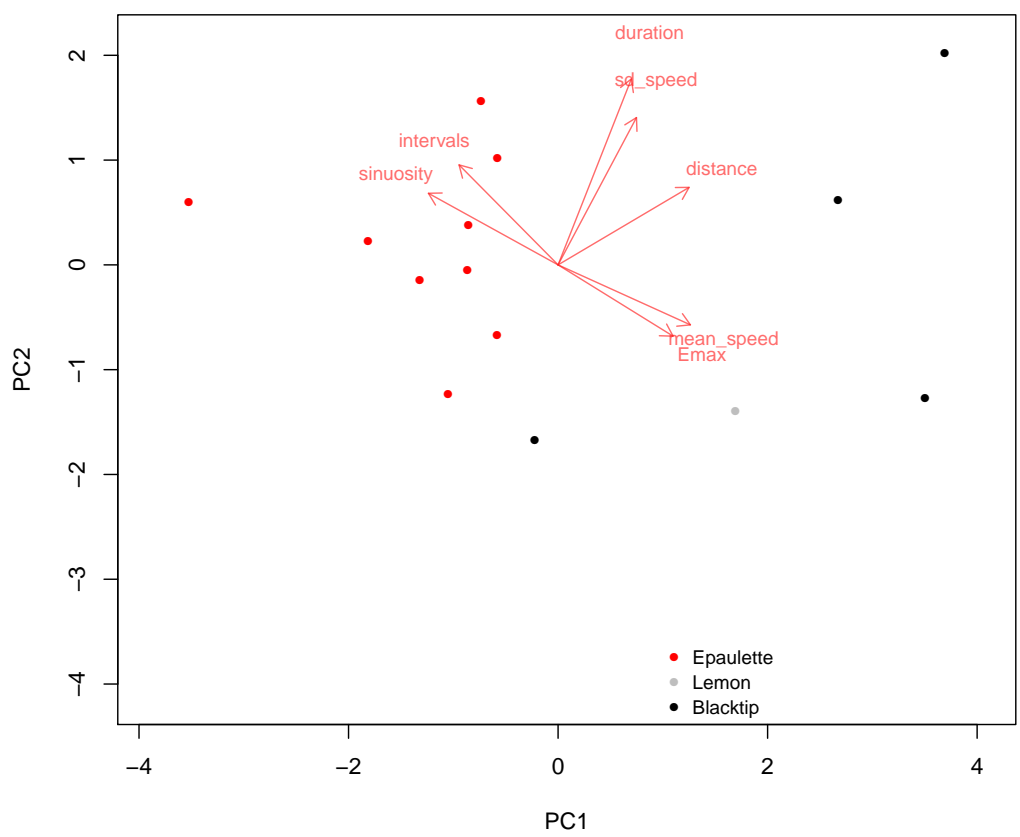

Figure 5. Principle correspondence analysis of the outputs of trajectory analyses from UAV-tracked sharks in Heron Island reef crest.

\section{Discussion}

This study demonstrates that UAV-based tracking is a prospective tool in obtaining information on the spatial and temporal movement of marine animals at high resolutions. UAVs have previously been trialled in shallow inshore areas to obtain information about distribution patterns and inter and intraspecific behaviours of large marine vertebrates [43,45]. However, the potential of UAVs to effectively track movement and record the behaviour of marine vertebrates has only been assessed using hover flight over specific structures [4]. Understanding the small-scale movement, habitat use, and fine-scale foraging behaviour of larger vertebrates can help to guide the management of these habitats, yet these data are inherently difficult to obtain. To date, information on small-scale movement of marine animals is usually acquired with acoustic tags via an array of fixed receivers [67] or active tracking of the animal with a manually driven vessel [32]. More recently, VEMCO high residence tags and receivers (HR-VPS) present positional data on aquatic animals at high temporal resolutions and fine-scales [68]. However, these methods are labour-intensive either in terms of 
deploying and maintaining receivers or tracking animals, require invasive surgery, and are expensive due to tag (often single-use) and receiver costs. Utilising a UAV is noninvasive technique that does not require the deployment of fixed structures and is relatively cost-effective, given that the predominant expense is the one-off purchase of a drone. Furthermore, while acoustic telemetry and active tracking provide fine scale positioning and habitat utilisation, the noncontinuous timepoints at which data are obtained (generally every 1-3 min at best, Espinoza et al. [67]) fail to provide information about when animals are feeding and why an animal is altering its trajectory and speed. Being able to assess this in real time continuously, coupled with a previously georeferenced assessment of the surrounding habitat, should enable researchers to infer immediate relationships between habitat and behaviour [69]. While combining tagging with technologies such as Crittercam [70] can effectively bridge this gap, the cost and requirement of tagging the animals remains. Our study demonstrates that UAV technology is a cost-effective tool for obtaining high-resolution information on the movement and behaviour of marine vertebrates, providing utilisation data of habitats such as the reef flat. We suggest that movement studies relying on satellite and/or acoustic tags on animals visible from the surface consider the addition of UAV tracking to provide additional, continuous higher-resolution movement and behaviour data in areas of interest, or when tagging is unfeasible or undesirable.

The drone-based tracking approach demonstrated here proved to be an effective tool to track the fine-scale movements and behaviours of marine vertebrates in shallow reef environments. While the number of animals tracked here is too small to infer ecological patterns, the data provided by these analyses demonstrate the potential for this approach. Analysis of shark trajectories in our research revealed a high variation in movement patterns within and between species. Mesopelagic shark movement patterns were more linear than the more sinuous movement patterns of benthic Epaulette sharks. One broad objective was to determine whether the movement patterns of Epaulette sharks were restricted to higher tides, and if these movements were predominantly nocturnal and crepuscular, as studies have suggested [52,53]. Epaulette sharks observed during low tides were highly active, with mean movement rates of $0.38 \mathrm{~m} \cdot \mathrm{s}^{-1}$ and a maximum tracked distance of $222 \mathrm{~m}$ over roughly $10 \mathrm{~min}$. Previous research had indicated that the habitat ranges of these sharks were relatively restricted (30-49 $\mathrm{m}$ in Heupel and Bennett [53] over 1-725 days). While our results do not provide information on residency, they suggest that Epaulette sharks are highly active within their habitat ranges. Since all our observations were conducted during daylight, our results also imply that Epaulette movement is not exclusively crepuscular and nocturnal [52]. Three natural feeding events across all tracked sharks were recorded. The approach provided in this study was a suitable means to extract high-resolution movement data of sharks in a shallow reef environment and would likely be useful in shallow beach environments where human-shark interactions frequently occur. Clearly, longer tracking trajectories and larger sample sizes are needed here to verify these behaviours, and UAV technology provides an exciting proposition for further exploring the behaviour of these marine vertebrates.

\section{Considerations for Use of This Methodology}

Drone-based animal tracking provides many benefits over conventional tracking approaches, but there are limitations in its use. Chief among those is the limited battery life of current drones, which limits the upper extent of tracking time. With the previous-generation DJI Phantom 3 Pro used here, tracking time was effectively limited to $\sim 15 \mathrm{~min}$ at the most in ideal conditions. The current-generation DJI Phantom 4 Pros would extend that track time to $\sim 25 \mathrm{~min}$, and consistent improvements in battery and drone technology should continually increase this maximum track time. Pilot fatigue can then become a limitation, as tracking in this fashion requires constant flight inputs and concentration. Even if battery technology allows longer flights, expecting tracks of over an hour using this approach may be unfeasible with the use of one UAV and pilot. An alternate to this would be to have several drones and pilots that take turns flying over the animal. While we saw no clear patterns of change in behaviour once we positioned the UAV above the animals, direct testing examining UAV impacts on behaviour should be conducted and may vary between species, though recent studies have 
found that the noise effects of UAVs underwater are minor [71] and a recent review suggests small electric UAVs like the one here are unlikely to have an impact [72]. Weather conditions can also limit the use of this methodology, since wind clutter on the water's surface reduces visibility. We found wind speeds of less than 10 knots were ideal, though tracking could occur in up to 17 knot winds, and the approaches described in detail in Joyce et al. [73] will help users to limit the environmental effects during drone flights. Finally, since drones can only record horizontal movement of animals in this manner, the vertical movements of the animals are not recorded.

\section{Conclusions}

Understanding the spatial dynamics of animal populations is a core aspect of conservation and management. While acoustic and pop-up archival tagging can provide information about movement speeds and habitat preferences at small scales, the high costs of these approaches, stress to animals from the tagging process, and lower resolution preclude their use in some scenarios. Obtaining information on the frequency of feeding events as well as the microhabitats that are being utilised can provide further information on their ecology and drive the management of these animals. This is particularly important in areas that have high human/marine vertebrate interactions, such as inshore reef flats or shallow coastal areas. The use of drone-based animal tracking should allow the expansion of new research areas and, in conjunction with acoustic and satellite tagging approaches, help to build cohesive life-histories of marine vertebrates.

Supplementary Materials: The following are available online at http://www.mdpi.com/2504-446X/2/4/37/s1, SharkTracking.r, script for the analyses performed here.

Author Contributions: Conceptualization, V.R. and J.E.W.; Formal analysis, V.R.; Methodology, V.R. and L.T.; Writing—original draft, V.R., L.T. and J.E.W.; Writing—review \& editing, V.R., L.T. and J.E.W.

Funding: This research received no external funding.

Acknowledgments: Many thanks to the staff at Heron Island Research Station for their assistance during numerous research trips. Thanks to Macquarie University students who assisted with drone spotting. This research was funded by the Department of Biological Sciences at Macquarie University. V. Raoult's salary was funded by the University of Newcastle. This research was conducted under Macquarie University's animal ethics research permit ARA 2016/019.

Conflicts of Interest: The authors declare no conflict of interest.

\section{References}

1. Nathan, R. An emerging movement ecology paradigm. Proc. Natl. Acad. Sci. USA 2008. [CrossRef] [PubMed]

2. Gunnarsson, T.G.; Gill, J.A.; Atkinson, P.W.; Gelinaud, G.; Potts, P.M.; Croger, R.E.; Gudmundsson, G.A.; Appleton, G.F.; Sutherland, W.J. Population-scale drivers of individual arrival times in migratory birds. J. Anim. Ecol. 2006, 75, 1119-1127. [CrossRef] [PubMed]

3. Fauchald, P.; Tveraa, T. Hierarchical patch dynamics and animal movement pattern. Oecologia 2006, 149, 383-395. [CrossRef] [PubMed]

4. Schofield, G.; Papafitsoros, K.; Haughey, R.; Katselidis, K. Aerial and underwater surveys reveal temporal variation in cleaning-station use by sea turtles at a temperate breeding area. Mar. Ecol. Prog. Ser. 2017, 575, 153-164. [CrossRef]

5. Benhamou, S. How to reliably estimate the tortuosity of an animal's path: Straightness, sinuosity, or fractal dimension? J. Theor. Biol. 2004, 229, 209-220. [CrossRef] [PubMed]

6. Phillips, M.L.; Clark, W.R.; Nusser, S.M.; Sovada, M.A.; Greenwood, R.J. Analysis of predator movement in prairie landscapes with contrasting grassland composition. J. Mammal. 2004, 85, 187-195. [CrossRef]

7. Gilby, B.L.; Olds, A.D.; Connolly, R.M.; Stevens, T.; Henderson, C.J.; Maxwell, P.S.; Tibbetts, I.R.; Schoeman, D.S.; Rissik, D.; Schlacher, T.A. Optimising land-sea management for inshore coral reefs. PLoS ONE 2016, 11, e0164934. [CrossRef] [PubMed]

8. Chapman, D.D.; Feldheim, K.A.; Papastamatiou, Y.P.; Hueter, R.E. There and back again: A review of residency and return migrations in sharks, with implications for population structure and management. Аnпu. Rev. Mar. Sci. 2015, 7, 547-570. [CrossRef] [PubMed] 
9. Braccini, M.; Aires-da-Silva, A.; Taylor, I. Incorporating movement in the modelling of shark and ray population dynamics: Approaches and management implications. Rev. Fish. Biol. Fish. 2016, 26, 13-24. [CrossRef]

10. Taylor, M.D.; Babcock, R.C.; Simpfendorfer, C.A.; Crook, D.A. Where technology meets ecology: Acoustic telemetry in contemporary Australian aquatic research and management. Mar. Freshw. Res. 2017, 68, 1397-1402. [CrossRef]

11. Hart, C.E.; Blanco, G.S.; Coyne, M.S.; Delgado-Trejo, C.; Godley, B.J.; Jones, T.T.; Resendiz, A.; Seminoff, J.A.; Witt, M.J.; Nichols, W.J. Multinational tagging efforts illustrate regional scale of distribution and threats for east pacific green turtles (Chelonia mydas agassizii). PLoS ONE 2015, 10, e0116225. [CrossRef] [PubMed]

12. Bestley, S.; Jonsen, I.D.; Hindell, M.A.; Harcourt, R.G.; Gales, N.J. Taking animal tracking to new depths: Synthesizing horizontal-vertical movement relationships for four marine predators. Ecology 2015, 96, 417-427. [CrossRef] [PubMed]

13. Weng, K.C.; Foley, D.G.; Ganong, J.E.; Perle, C.; Shillinger, G.L.; Block, B.A. Migration of an upper trophic level predator, the salmon shark Lamna ditropis, between distant ecoregions. Mar. Ecol. Prog. Ser. 2008, 372, 253-264. [CrossRef]

14. Gore, M.A.; Rowat, D.; Hall, J.; Gell, F.R.; Ormond, R.F. Transatlantic migration and deep mid-ocean diving by basking shark. Biol. Lett. 2008, 4, 395-398. [CrossRef] [PubMed]

15. Vaudo, J.J.; Byrne, M.E.; Wetherbee, B.M.; Harvey, G.M.; Shivji, M.S. Long-term satellite tracking reveals region-specific movements of a large pelagic predator, the shortfin mako shark, in the western north Atlantic Ocean. J. Appl. Ecol. 2017, 54, 1765-1775. [CrossRef]

16. Domeier, M.L.; Nasby-Lucas, N. Two-year migration of adult female white sharks (Carcharodon carcharias) reveals widely separated nursery areas and conservation concerns. Anim. Biotelem. 2013, 1, 1-10. [CrossRef]

17. Heupel, M.; Simpfendorfer, C. Using acoustic monitoring to evaluate MPAS for shark nursery areas: The importance of long-term data. Mar. Technol. Soc. J. 2005, 39, 10-18. [CrossRef]

18. Garrigue, C.; Clapham, P.J.; Geyer, Y.; Kennedy, A.S.; Zerbini, A.N. Satellite tracking reveals novel migratory patterns and the importance of seamounts for endangered south pacific humpback whales. R. Soc. Open Sci. 2015, 2, 150489. [CrossRef] [PubMed]

19. Heupel, M.R.; Lédée, E.J.; Simpfendorfer, C.A. Telemetry reveals spatial separation of co-occurring reef sharks. Mar. Ecol. Prog. Ser. 2018, 589, 179-192. [CrossRef]

20. Mourier, J.; Maynard, J.; Parravicini, V.; Ballesta, L.; Clua, E.; Domeier, M.L.; Planes, S. Extreme inverted trophic pyramid of reef sharks supported by spawning groupers. Curr. Biol. 2016, 26, 2011-2016. [CrossRef] [PubMed]

21. Brough, T.; Rayment, W.; Slooten, E.; Dawson, S. Fine scale distribution for a population of New Zealand's only endemic dolphin (Cephalorhynchus hectori) shows long-term stability of coastal hotspots. Mar. Mamm. Sci. 2018. [CrossRef]

22. Meyer, C.G.; Anderson, J.M.; Coffey, D.M.; Hutchinson, M.R.; Royer, M.A.; Holland, K.N. Habitat geography around Hawaii's oceanic islands influences tiger shark (Galeocerdo cuvier) spatial behaviour and shark bite risk at ocean recreation sites. Sci. Rep. 2018, 8, 4945. [CrossRef] [PubMed]

23. Kock, A.A.; Photopoulou, T.; Durbach, I.; Mauff, K.; Meÿer, M.; Kotze, D.; Griffiths, C.L.; O’Riain, M.J. Summer at the beach: Spatio-temporal patterns of white shark occurrence along the inshore areas of false bay, South Africa. Mov. Ecol. 2018, 6, 7. [CrossRef] [PubMed]

24. Tyminski, J.P.; de la Parra-Venegas, R.; Cano, J.G.; Hueter, R.E. Vertical movements and patterns in diving behavior of whale sharks as revealed by pop-up satellite tags in the eastern gulf of Mexico. PLoS ONE 2015, 10, e0142156. [CrossRef] [PubMed]

25. Schlaff, A.M.; Heupel, M.R.; Udyawer, V.; Simpfendorfer, C.A. Biological and environmental effects on activity space of a common reef shark on an inshore reef. Mar. Ecol. Prog. Ser. 2017, 571, 169-181. [CrossRef]

26. Armansin, N.; Lee, K.; Huveneers, C.; Harcourt, R. Integrating social network analysis and fine-scale positioning to characterize the associations of a benthic shark. Anim. Behav. 2016, 115, 245-258. [CrossRef]

27. Johnson, M.; de Soto, N.A.; Madsen, P.T. Studying the behaviour and sensory ecology of marine mammals using acoustic recording tags: A review. Mar. Ecol. Prog. Ser. 2009, 395, 55-73. [CrossRef]

28. Wilson, A.D.; Brownscombe, J.W.; Krause, J.; Krause, S.; Gutowsky, L.F.; Brooks, E.J.; Cooke, S.J. Integrating network analysis, sensor tags, and observation to understand shark ecology and behavior. Behav. Ecol. 2015, 26, 1577-1586. [CrossRef] 
29. Wilson, R.P.; Liebsch, N.; Davies, I.M.; Quintana, F.; Weimerskirch, H.; Storch, S.; Lucke, K.; Siebert, U.; Zankl, S.; Müller, G. All at sea with animal tracks; methodological and analytical solutions for the resolution of movement. Deep Sea Res. Part II 2007, 54, 193-210. [CrossRef]

30. Huveneers, C.; Simpfendorfer, C.A.; Kim, S.; Semmens, J.M.; Hobday, A.J.; Pederson, H.; Stieglitz, T.; Vallee, R.; Webber, D.; Heupel, M.R. The influence of environmental parameters on the performance and detection range of acoustic receivers. Methods Ecol. Evol. 2016, 7, 825-835. [CrossRef]

31. Gunn, J.; Stevens, J.; Davis, T.; Norman, B. Observations on the short-term movements and behaviour of whale sharks (Rhincodon typus) at ningaloo reef, Western Australia. Mar. Biol. 1999, 135, 553-559. [CrossRef]

32. Carlisle, A.B.; Starr, R.M. Habitat use, residency, and seasonal distribution of female leopard sharks Triakis semifasciata in Elkhorn Slough, California. Mar. Ecol. Prog. Ser. 2009, 380, 213-228. [CrossRef]

33. Scales, K.L.; Lewis, J.; Lewis, J.; Castellanos, D.; Godley, B.; Graham, R. Insights into habitat utilisation of the hawksbill turtle, Eretmochelys imbricata (linnaeus, 1766), using acoustic telemetry. J. Exp. Mar. Biol. Ecol. 2011, 407, 122-129. [CrossRef]

34. Bouyoucos, I.; Suski, C.; Mandelman, J.; Brooks, E. Effect of weight and frontal area of external telemetry packages on the kinematics, activity levels and swimming performance of small-bodied sharks. J. Fish. Biol. 2017, 90, 2097-2110. [CrossRef] [PubMed]

35. Bullock, R.; Guttridge, T.; Cowx, I.; Elliott, M.; Gruber, S. The behaviour and recovery of juvenile lemon sharks Negaprion brevirostris in response to external accelerometer tag attachment. J. Fish. Biol. 2015, 87, 1342-1354. [CrossRef] [PubMed]

36. Hays, G.C.; Ferreira, L.C.; Sequeira, A.M.; Meekan, M.G.; Duarte, C.M.; Bailey, H.; Bailleul, F.; Bowen, W.D.; Caley, M.J.; Costa, D.P. Key questions in marine megafauna movement ecology. Trends Ecol. Evol. 2016, 31, 463-475. [CrossRef] [PubMed]

37. Gendron, D.; Serrano, I.M.; de la Cruz, A.U.; Calambokidis, J.; Mate, B. Long-term individual sighting history database: An effective tool to monitor satellite tag effects on cetaceans. Endanger. Spec. Res. 2015, 26, 235-241. [CrossRef]

38. Fontes, J.; Baeyaert, J.; Prieto, R.; Graça, G.; Buyle, F.; Afonso, P. New non-invasive methods for short-term electronic tagging of pelagic sharks and rays. Mar. Biol. 2018, 165, 34. [CrossRef]

39. Fregosi, S.; Klinck, H.; Horning, M.; Costa, D.P.; Mann, D.; Sexton, K.; Hückstädt, L.A.; Mellinger, D.K.; Southall, B.L. An animal-borne active acoustic tag for minimally invasive behavioral response studies on marine mammals. Anim. Biotelem. 2016, 4, 9. [CrossRef]

40. Pirotta, V.; Smith, A.; Ostrowski, M.; Russell, D.; Jonsen, I.D.; Grech, A.; Harcourt, R. An economical custom-built drone for assessing whale health. Front. Mar. Sci. 2017, 4, 425. [CrossRef]

41. Gallagher, A.J.; Papastamatiou, Y.P.; Barnett, A. Apex predatory sharks and crocodiles simultaneously scavenge a whale carcass. J. Ethol. 2018, 36, 205-209. [CrossRef]

42. Colefax, A.P.; Butcher, P.A.; Kelaher, B.P.; Browman, H.E.H. The potential for unmanned aerial vehicles (UAVs) to conduct marine fauna surveys in place of manned aircraft. ICES J. Mar. Sci. 2017, 75, 1-8. [CrossRef]

43. Christiansen, F.; Dujon, A.M.; Sprogis, K.R.; Arnould, J.P.; Bejder, L. Noninvasive unmanned aerial vehicle provides estimates of the energetic cost of reproduction in humpback whales. Ecosphere 2016, 7. [CrossRef]

44. Kiszka, J.J.; Mourier, J.; Gastrich, K.; Heithaus, M.R. Using unmanned aerial vehicles (UAVs) to investigate shark and ray densities in a shallow coral lagoon. Mar. Ecol. Prog. Ser. 2016, 560, 237-242. [CrossRef]

45. Rieucau, G.; Kiszka, J.J.; Castillo, J.C.; Mourier, J.; Boswell, K.M.; Heithaus, M.R. Using unmanned aerial vehicle (UAV) surveys and image analysis in the study of large surface-associated marine species: A case study on reef sharks Carcharhinus melanopterus shoaling behaviour. J. Fish. Biol. 2018, 93, 119-127. [CrossRef] [PubMed]

46. Gore, M.; Abels, L.; Wasik, S.; Saddler, L.; Ormond, R. Are close-following and breaching behaviours by basking sharks at aggregation sites related to courtship? J. Mar. Biol. Assoc. UK 2018, 1-13. [CrossRef]

47. Cárdenas, N.Y.; Joyce, K.E.; Maier, S.W. Monitoring mangrove forests: Are we taking full advantage of technology? Int. J. Appl. Earth Obs. Geoinf. 2017, 63, 1-14. [CrossRef]

48. Last, P.R.; Stevens, J.D. Sharks and Rays of Australia; CSIRO Publishing: Collingwood, Australia, 2009.

49. Routley, M.H.; Nilsson, G.E.; Renshaw, G.M. Exposure to hypoxia primes the respiratory and metabolic responses of the epaulette shark to progressive hypoxia. Comp. Biochem. Physiol. A Mol. Integr. Physiol. 2002, 131, 313-321. [CrossRef] 
50. Wise, G.; Mulvey, J.M.; Renshaw, G.M. Hypoxia tolerance in the epaulette shark (Hemiscyllium ocellatum). J. Exp. Zool. 1998, 281, 1-5. [CrossRef]

51. Hickey, A.J.; Renshaw, G.M.; Speers-Roesch, B.; Richards, J.G.; Wang, Y.; Farrell, A.P.; Brauner, C.J. A radical approach to beating hypoxia: Depressed free radical release from heart fibres of the hypoxia-tolerant epaulette shark (Hemiscyllum ocellatum). J. Comp. Physiol. B 2012, 182, 91-100. [CrossRef] [PubMed]

52. Heupel, M.; Bennett, M. Observations on the diet and feeding habits of the epaulette shark, Hemiscyllium ocellatum (bonnaterre), on heron island reef, Great Barrier Reef, Australia. Mar. Freshw. Res. 1998, 49, 753-756. [CrossRef]

53. Heupel, M.; Bennett, M. Estimating abundance of reef-dwelling sharks: A case study of the epaulette shark, Hemiscyllium ocellatum (elasmobranchii: Hemiscyllidae). Pac. Sci. 2007, 61, 383-394. [CrossRef]

54. Papastamatiou, Y.P.; Lowe, C.G.; Caselle, J.E.; Friedlander, A.M. Scale-dependent effects of habitat on movements and path structure of reef sharks at a predator-dominated atoll. Ecology 2009, 90, 996-1008. [CrossRef] [PubMed]

55. Bird, C.S.; Veríssimo, A.; Magozzi, S.; Abrantes, K.G.; Aguilar, A.; Al-Reasi, H.; Barnett, A.; Bethea, D.M.; Biais, G.; Borrell, A. A global perspective on the trophic geography of sharks. Nat. Ecol. Evol. 2018. [CrossRef] [PubMed]

56. Gallagher, A.J.; Shiffman, D.S.; Byrnes, E.E.; Hammerschlag-Peyer, C.; Hammerschlag, N. Patterns of resource use and isotopic niche overlap among three species of sharks occurring within a protected subtropical estuary. Aquat. Ecol. 2017, 51, 435-448. [CrossRef]

57. Guttridge, T.L.; van Dijk, S.; Stamhuis, E.J.; Krause, J.; Gruber, S.H.; Brown, C. Social learning in juvenile lemon sharks, Negaprion brevirostris. Anim. Cogn. 2013, 16, 55-64. [CrossRef] [PubMed]

58. Williamson, J.E.; Byrnes, E.E.; Clark, J.A.; Connolly, D.M.; Schiller, S.E.; Thompson, J.A.; Tosetto, L.; Martinelli, J.C.; Raoult, V. Ecological impacts and management implications of reef walking on a tropical reef flat community. Mar. Pollut. Bull. 2017, 114, 742-750. [CrossRef] [PubMed]

59. Gennari, E.; Cowley, P.D.; Johnson, R.L. Performance and reliability of active acoustic biotelemetry to best track marine pelagic species in temperate coastal waters. Mar. Biol. 2018, 165, 128. [CrossRef]

60. Hugenholtz, C.; Brown, O.; Walker, J.; Barchyn, T.; Nesbit, P.; Kucharczyk, M.; Myshak, S. Spatial accuracy of UAV-derived orthoimagery and topography: Comparing photogrammetric models processed with direct geo-referencing and ground control points. Geomatica 2016, 70, 21-30. [CrossRef]

61. Ferraript. Txtlogtocsvtool. 2018. Available online: https://phantompilots.com/attachments/txtlogtocsvtoolzip.98013/ (accessed on 21 April 2018).

62. R Development Core Team. R: A Language and Environment for Statistical Computing; R Foundation for Statistical Computing: Vienna, Austria, 2013.

63. Khale, D.; Wickham, H. Ggmap: Spatial visualization with ggplot2. R J. 2013, 5, 144-161.

64. Michelot, T.; Langrock, R.; Patterson, T.A. Movehmm: An r package for the statistical modelling of animal movement data using hidden markov models. Methods Ecol. Evol. 2016, 7, 1308-1315. [CrossRef]

65. Albertsen, C.M.; Whoriskey, K.; Yurkowski, D.; Nielsen, A.; Flemming, J.M. Fast fitting of non-gaussian state-space models to animal movement data via template model builder. Ecology 2015, 96, 2598-2604. [CrossRef] [PubMed]

66. McLean, D.J.; Skowron Volponi, M.A. Trajr: An r package for characterisation of animal trajectories. Ethology 2018. [CrossRef]

67. Espinoza, M.; Farrugia, T.J.; Webber, D.M.; Smith, F.; Lowe, C.G. Testing a new acoustic telemetry technique to quantify long-term, fine-scale movements of aquatic animals. Fish. Res. 2011, 108, 364-371. [CrossRef]

68. Guzzo, M.M.; Van Leeuwen, T.E.; Hollins, J.; Koeck, B.; Newton, M.; Webber, D.M.; Smith, F.I.; Bailey, D.M.; Killen, S.S. Field testing a novel high residence positioning system for monitoring the fine-scale movements of aquatic organisms. Methods Ecol. Evol. 2018, 9, 1478-1488. [CrossRef] [PubMed]

69. Wich, S.A.; Koh, L.P. Conservation Drones: Mapping and Monitoring Biodiversity; Oxford University Press: Oxford, UK, 2018.

70. Heithaus, M.R.; Marshall, G.J.; Buhleier, B.M.; Dill, L.M. Employing crittercam to study habitat use and behavior of large sharks. Mar. Ecol. Prog. Ser. 2001, 209, 307-310. [CrossRef]

71. Christiansen, F.; Rojano-Doñate, L.; Madsen, P.T.; Bejder, L. Noise levels of multi-rotor unmanned aerial vehicles with implications for potential underwater impacts on marine mammals. Front. Mar. Sci. 2016, 3, 277. [CrossRef] 
72. Mulero-Pázmány, M.; Jenni-Eiermann, S.; Strebel, N.; Sattler, T.; Negro, J.J.; Tablado, Z. Unmanned aircraft systems as a new source of disturbance for wildlife: A systematic review. PLOS ONE 2017, 12, e0178448. [CrossRef] [PubMed]

73. Joyce, K.; Duce, S.; Leahy, S.; Leon, J.X.; Maier, S. Principles and practice of acquiring drone based image data in marine environments. Mar. Freshw. Res. 2018. [CrossRef]

(c)

(C) 2018 by the authors. Licensee MDPI, Basel, Switzerland. This article is an open access article distributed under the terms and conditions of the Creative Commons Attribution (CC BY) license (http://creativecommons.org/licenses/by/4.0/). 